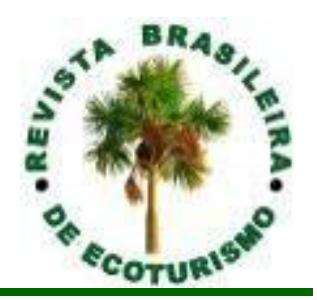

\title{
Birdwatching como uma proposta de valorização do espaço ecoturístico da Lagoa Rodrigo de Freitas, Rio de Janeiro (RJ)
}

\section{Birdwatching as a proposal to enhance the ecotourism space of Lagoa Rodrigo de Freitas, Rio de Janeiro (RJ, Brazil)}

\author{
José Antônio Dias da Silva
}

\begin{abstract}
RESUMO: Como um experimento voltado à cidadania científica, o presente artigo propõe a criação de um projeto envolvendo a participação de observadores de aves no levantamento, monitoramento e preservação das espécies que compõem a comunidade de aves da Lagoa Rodrigo de Freitas. Regulamentada como Área de Proteção Permanente em 2008, a Lagoa e o seu espaço circundante é considerado um dos principais pontos turísticos da cidade do Rio de Janeiro. A observação de aves (birdwatching) é uma atividade que vem crescendo ultimamente em diversos países e tem se constituído no principal alicerce do que chamamos ciência cidadã. Pelo último levantamento aqui apresentado, a Lagoa possui um total de 39 espécies de aves pertencentes a 23 famílias. Desse total, 10 são aquáticas e 29 são terrestres. A proposta do artigo consiste em desenvolver um projeto particular de preservação das aves da Lagoa a partir da colaboração dos observadores de aves, os quais participarão ativamente no levantamento, monitoramento e divulgação de informações. A primeira etapa do projeto será atualizar a lista de aves assinalando a presença sazonal das espécies, conforme mostrado neste trabalho. As etapas posteriores envolvem a descrição de hábitos e comportamentos dos espécimens, marcação de pontos de melhor avistamento dos indivíduos e a divulgação periódica da situação do conjunto de aves do local. Os dados recolhidos poderão ser depositados em plataformas digitais como o Wiki Aves e o Táxeus. Ao permitir a participação ativa dos cidadãos em atividades científicas, a ciência cidadã tem contribuído intensamente para a expansão do conhecimento científico, gerando experiência, compreensão e novos conhecimentos tanto para a ciência quanto para o cidadão participante.
\end{abstract}

PALAVRAS CHAVE: Aves; Birdwatching; Ciência Cidadã; Ecoturismo; Ecossistemas Aquáticos 
ABSTRACT: As a sciencific citizenship experiment, this article proposes the creation of a project involving the participation of birdwatchers in the survey, monitoring and preservation of the species that make up the Rodrigo de Freitas Lagoon birds community. Regulated as a Permanent Protection Area in 2008, Lagoon and its surrounding space is considered one of the main tourist spots in the city of Rio de Janeiro. Birdwatching is an activity that has been growing recently in several countries and has been the main foundation of citizen science. For the last survey presented here, the Lagoon has a total of 39 species of birds belonging to 23 families. Of this total, 10 are aquatic and 29 are terrestrial. The purpose of the article is to develop a private project for the preservation of the birds of the Lagoon based on the collaboration of bird watchers, who will actively participate in the survey, monitoring and dissemination of information. The first stage of the project will be to update the list of birds indicating the seasonal presence of the species as shown in this work. The subsequent steps involve the description of habits and behaviours of the specimens, marking points for the best sighting of the individuals and the periodic disclosure of the situation of the group of birds in the place. The collected data may be deposited on digital platforms such as Wiki Aves and Táxeus. Citizen science has contributed intensively to the expansion of scientific knowledge, allowing the active participation of citizens in scientific activities, generating experience, understanding and new knowledge for both science and the participating citizen.

KEYWORDS: Aquatic Ecosystems; Birds; Birdwatching; Citizen Science; Ecotourism.

\section{Introdução}

Lagos e lagoas são vistos como importantes pontos de refúgios para aves, não só como local de abrigo para espécies residentes, mas também como sítio de alimentação, reprodução e repouso para uma grande quantidade de aves migratórias. Porém, muitos recursos alimentares são sazonais e muitas espécies animais, incluindo aves, apresentam flutuações sazonais associadas a estes recursos.

Localizadas em áreas urbanizadas, entre a costa e o mar, as lagoas costeiras do Estado do Rio de Janeiro são ambientes submetidos a forte estresse, em função das diversas atividades humanas concentradas em seu entorno. Os impactos desta ação antrópica têm transformado a maioria das lagoas costeiras em ambientes com elevados processos de eutrofização, decorrente de lançamento de carga orgânica, representada por formas químicas de nitrogênio e fósforo. Como consequência, verifica-se constantemente a ocorrência de florações de microalgas, espumas de algas, de águas com coloração variada e turvejadas, crescimento de bancos de plantas aquáticas, de fortes odores e a depleção repentina de oxigênio, além da possibilidade de eventos de mortandade de peixes (SANTORO; RICCl; ENRICH-PRAST, 2012, p.336).

$\mathrm{Na}$ região sudeste os sistemas lacunares encontram-se seriamente afetados pelo desenvolvimento urbano, pelas atividades de recreação e pelo turismo. Assim sendo, o aumento ou decréscimo das populações de aves aquáticas tem sido usado como indicador da qualidade de água e consequentemente da qualidade ambiental, uma vez que a presença ou ausência de certas espécies, bem como as tendências populacionais podem ser usadas como indicadores da qualidade ambiental (RUTSCHKE, 1987; GOLDSMITH, 1991; FURNESS et al. 1993). Isto porque estas populações são influenciadas por mínimas alterações do habitat como drenagem, aterramento, desmatamento, sobrepesca, poluição, e alterações do fluxo de água como aqueles provenientes de construções de barreiras. 
A Lagoa Rodrigo de Freitas e todo o seu espaço circundante representam hoje uma das principais referências turísticas da Cidade do Rio de Janeiro. Em 2008, esse espaço foi regulamentado como Área de Proteção Permanente e o seu espelho d'água tombado desde os anos 1990. Em 2010, ocorreu nas dependências da Universidade Federal do Rio de Janeiro (U.F.R.J.), um simpósio intitulado "Lagoa Rodrigo de Freitas: Passado, Presente e Futuro", o qual reuniu pesquisadores, estudantes, sociedade civil, iniciativa privada e representantes do Poder Público e teve como objetivo debater o futuro deste ambiente a luz do conhecimento já existente de sua ecologia e dinâmica. $\mathrm{Na}$ ocasião, diversas sugestões de solução para a melhoria da qualidade ambiental foram apresentadas, esclarecidas e debatidas em três dias de encontro (SANTORO; RICCI; ENRICH-PRAST, 2012, p. 336).

Porém, passados dez anos do Simpósio, a Lagoa continua enfrentando problemas devido a sua complexidade de gestão que envolve os seus múltiplos usos, interesses e agentes, necessitando de projetos efetivos de melhoria da sua qualidade ambiental e de valorização do seu potencial ecoturístico. Nesse particular, o presente artigo vem propor a implantação de atividades programadas de observação de aves (birdwatching) visando o monitoramento e a conservação das espécies da comunidade de aves da Lagoa a partir da contribuição dos próprios observadores como acontece nas iniciativas de cidadania científica (STOKES, 2005).

O birdwatching é uma atividade que consiste em obter registros visuais ou sonoros das aves, e até mesmo fotografá-las em seu ambiente natural, realizada por muitos como atividade de lazer (ALEXANDRINO; QUEIROZ; MASSARUTTO, 2012; BERNARDON; NASSAR, 2012). Para registrar estas informações, é comum a utilização de binóculos e máquinas fotográficas ou mesmo câmeras de telefone celulares e, as espécies também podem ser identificadas através de suas vocalizações, com gravações para análises da espécie. Além disso, existem atualmente plataformas on line específicas como a Wiki Aves e o Táxeus que permitem a identificação das espécies em campo e o compartilhamento de informações bioecológicas a respeito da avifauna brasileira em tempo real (SILVA; NERY, 2019).

Segundo Dias (2011, p.114) o turismo com finalidade ornitológica constitui uma das atividades em acelerado crescimento, pois envolve de modo concreto o visitante com uma prática ecológica que antecede e se estende muito além da visitação, exigindo preparo, planejamento e posterior avaliação. Tecnicamente, vários autores também ressaltam que o birdwatching é uma atividade associada ao ecoturismo que exige conhecimento especializado em ornitologia, levantamentos periódicos da avifauna local, monitoramento e identificação das espécies e a integração do turista em diversas redes de acompanhamento de grupos específicos de aves (DIAS; FIGUEIRA, 2010; DIAS, 2011; SANTOS et al. 2019).

O presente estudo tem como objetivo propor um programa de integração dos observadores de aves à dinâmica da comunidade de aves da Lagoa Rodrigo de Freitas por meio da participação efetiva no monitoramento, levantamento e acompanhamento dos hábitos e comportamentos das espécies que dependem desse sistema lacunar. A proposta inclui a elaboração de listas atualizadas das espécies, registros de hábitos alimentares, identificação e marcação de locais de pousada, dormitórios e áreas de nidificação das espécies e acompanhamento da presença sazonal, além do compartilhamento dessas informações em plataformas e bancos de dados visando a preservação das espécies, conforme as premissas dos projetos de ciência cidadã adotados em diversas partes do mundo (PARRA; FRESSOLI; LAFUENTE, 2017, p. 4). 


\section{Material e Métodos}

\section{Caracterização da área de estudo}

A Lagoa Rodrigo de Freitas está localizada no município do Rio de Janeiro

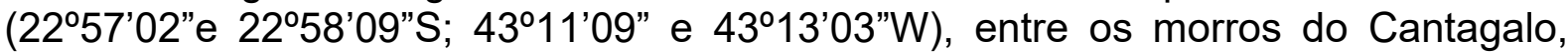
Cabritos e Saudade a leste, Morros do Corcovado e Sumaré ao norte e pelas praias de Ipanema e Leblon ao sul. Situada próxima ao Parque Nacional da Tijuca, a Lagoa pertence a uma cadeia de 11 grandes lagoas costeiras da qual fazem parte as lagoas de Jacarepaguá e de Araruama e está separada do mar por uma faixa de areia, comunicando-se com o mar pelo canal do Jardim de Alá (ALVES; PEREIRA, 1998 , p. 110). Com um perímetro aproximado de 7,2 quilômetros, a Lagoa possui um formato irregular (BRITO; LEMOS, 1982). O seu espelho d'água possui uma superfície aproximada de 233 hectare e um volume de 6.990 .000 metros cúbicos de água com uma profundidade máxima de 4,3 metros (Figura 1).

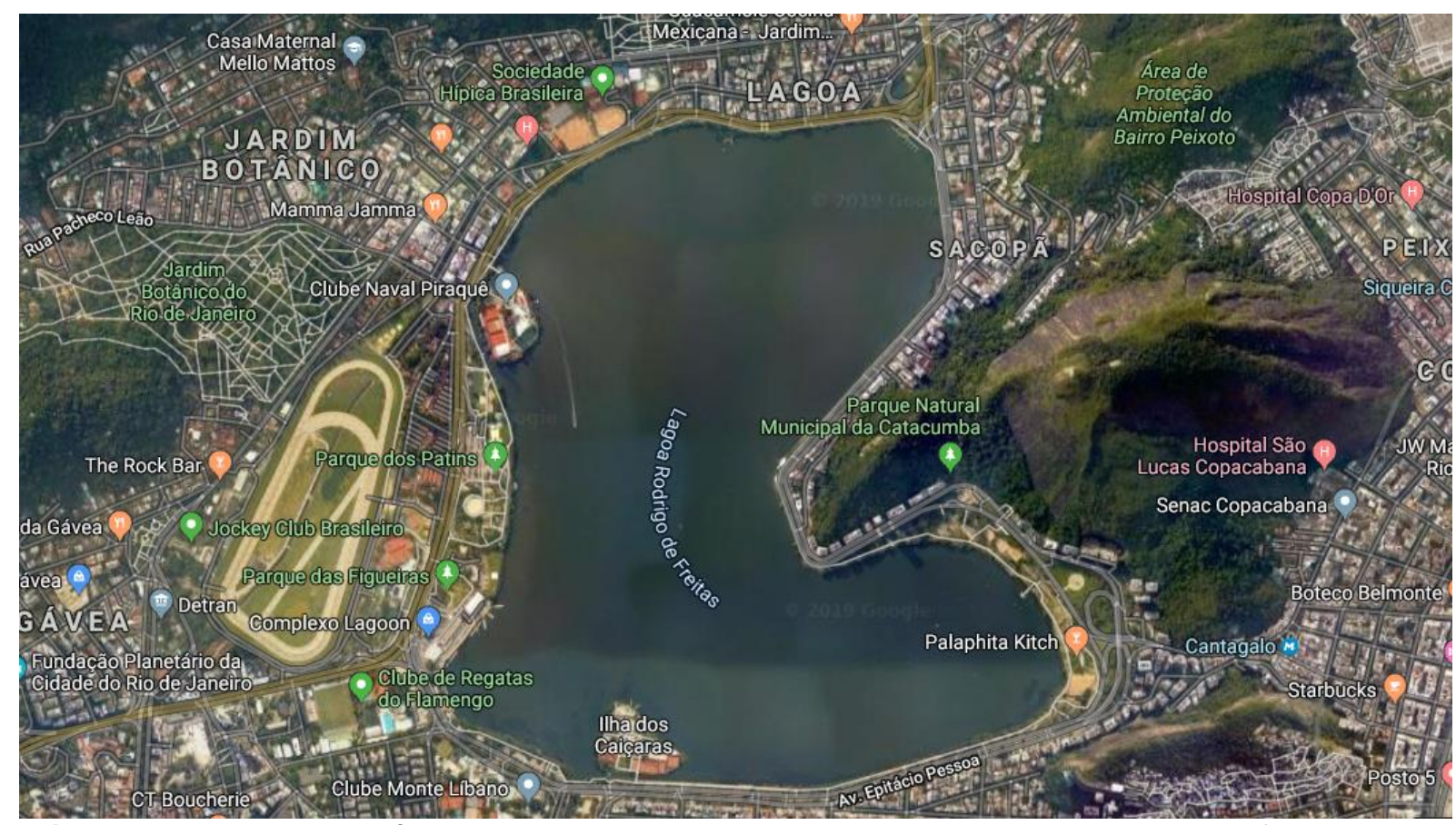

Figura 1: Imagem de satélite destacando a Lagoa Rodrigo de Freitas dentro da geografia da cidade do Rio de Janeiro. Fonte: Google Mapas

Figure 1: Satellite image highlighting Lagoa Rodrigo de Freitas within the geography of the city of Rio de Janeiro. Source: Google Maps

A Lagoa se inclui na categoria de lagoa sufocada, por apresentar uma única via de comunicação com o mar. Devido a ineficiente troca de suas águas com o mar, faz-se longo o tempo de residência de suas águas, o que gera um acúmulo de materiais em suspensão e matéria orgânica que aí aportam. Há registros de uma tênue estratificação bem junto ao fundo que impede a mistura de massas de água, tornando a camada salgada, rapidamente anaeróbica e rica em gases como metano e sulfeto, em consequência da matéria orgânica aí acumulada. 


\section{Metodologia}

Durante o período de janeiro de 2008 a janeiro de 2009 estimamos a riqueza das aves presentes na Lagoa Rodrigo de Freitas e em sua margem e reavaliamos o status residencial ou presença sazonal das espécies registradas nesta localidade por Alves e Pereira (1998). Para uma melhor caracterização da comunidade de aves deste sistema lacunar, consideramos como parte de tal comunidade, não somente as aves aquáticas, mas também todas as espécies associadas com a vegetação parcialmente inundada, bem como aquelas relacionadas com o solo e a vegetação ao longo da margem (ALVES; PEREIRA, 1998, p. 112).

Foram realizadas visitas periódicas ao local durante os 13 meses do estudo, em horários fixos, totalizando 32 visitas e aproximadamente 96 horas de observação (em dias chuvosos não foram feitas observações). As saídas de campo eram sempre efetuadas nos seguintes períodos: manhã (de 07:00 às 09:00 horas), tarde (de 12:00 às 14:00 horas) e fim de tarde (de 16:00 às 18:00 horas), alternadamente. Conforme o procedimento adotado por Alves e Pereira (1998, p. 112), dividimos a lagoa em seis seções imaginárias, cada uma com extensão aproximada de 1.200 metros ao longo da borda e a porção d'água correspondente (ALVES; PEREIRA, 1998, p. 112). Usamos estas seções da margem como transectos, os quais foram percorridos mensalmente, em horários diversos, durante todo o período de estudo.

O número de espécies (riqueza) foi obtido através de um censo por contagem direta (BIBBY; BURGESS; HILL, 1993) com anotações na caderneta de campo. Na ocasião, as espécies foram observadas e contabilizadas com auxílio de binóculos de $8 \times 40$ e identificadas com ajuda de guias de campo (HAYMAN, MARCHANT; PRATER, 1986; SICK, 1997; SOUZA, 2002). Em nossa lista, as espécies acrescidas à listagem anterior da comunidade de aves da Lagoa foram assinaladas por um asterisco $\left(^{*}\right)$. A nomenclatura científica e a ordenação taxionômica desse trabalho estão de acordo com Sick (1997) e o tratamento estatístico dos dados apurados foi efetuado conforme Zar (1984).

Para se determinar o status residencial ou presença sazonal das espécies registradas, utilizamos as mesmas categorias que foram estabelecidas por Rodrigues e Michelin (2005): (1) Residente (espécie registrada em pelo menos 90\% das visitas); (2) Visitante (espécie que só foi registrada em determinada época do ano, como por exemplo, numa determinada estação); (3) Provável residente (espécie que, por sua biologia e/ou ecologia poderia ser considerada residente, mas durante o estudo não foi registrada em todas as estações, não apresentando sazonalidade definida); (4) Indeterminada (espécie com presença sazonal não determinada, ou seja, que foram pouco registradas durante o trabalho e, por isso não se pode determinar sua sazonalidade). Além das categorias sazonais citadas, acrescentamos a de (5) Acidental (para aquelas espécies registradas em uma única vez em todas as visitas realizadas) conforme Brandolin et al (2007).

Associamos cada uma das categorias citadas acima a uma classe de valores obtidos em função da frequência observada ( $F o$ = porcentagem de avistamento das espécies em relação ao total de observações realizadas) da seguinte forma: (1) Residente (Fo entre 1 e 0,8); (2) Provável Residente (Fo entre 0,6 e 0,8); (3) Visitante (Fo entre 0,4 e 0,6; (4) Indeterminada (Fo entre 0,2 e 0,4) e (5) Acidental (Fo menor que 0,1 ).

A proposta de integração dos observadores de aves ao nosso projeto de levantamento, monitoramento e descrição dos hábitos das aves da Lagoa será 
conduzido da seguinte maneira: os participantes serão convocados a aderir ao nosso programa a partir de mensagens veiculadas nas redes sociais e por meio de cartazes fixados em agências de turismo e nos clubes de observadores de aves existentes. Uma vez devidamente cadastrados, os observadores ficarão encarregados de elaborar uma nova lista de aves da lagoa baseada nesse último levantamento que fizemos, além de incluir informações relevantes sobre as características biológicas e ecológicas observadas na comunidade de aves do local disponibilizando as informações para a equipe de gerenciamento do projeto. Posteriormente, os interessados poderão divulgar os seus registros em plataformas de dados ornitológicos como o Wiki Aves, Táxeus e eBird. O detalhamento do projeto será enviado aos participantes por meio de correio eletrônico (e-mail).

\section{Resultados e Discussão}

Um total de 39 espécies pertencentes a 23 famílias foi registrado durante o período de estudo. Das 39 espécies registradas, 10 são aquáticas e 29 são terrestres. As famílias com o maior número de espécies catalogadas foram: Tyrannidae ( 6 espécies), Ardeidae (5 espécies) e Emberezidae (4 espécies). As famílias com o menor número de espécies foram Columbidae e Muscicapidae, ambas representadas por duas espécies; as demais famílias foram representadas por apenas uma espécie. Sete espécies que não constavam da lista de Alves e Pereira (1998) foram acrescentadas. São elas: Gallinula galeata, Coragyps atratus, Furnarius rufus, Certhiaxis cinnamomea, Cantorchilus longirostris, Philohydor lictor, Paroaria dominicana e Molothrus bonariensis.

De acordo com o critério adotado no presente estudo, duas espécies acrescentadas foram classificadas como sendo residentes ( $G$. galeata e F. rufus), uma como provável residente (C. Cinnamomea), uma com presença sazonal indeterminada $(M$. bonariensis), uma como visitante $(C$. longirostris) e duas espécies foram consideradas acidentais (C. Atratus e $P$. dominicana).(Tabela 1$)$.

Tabela 1: Composição de espécies e presença sazonal da comunidade de aves da Lagoa Rodrigo de Freitas registradas no período de janeiro de 2008 a janeiro de 2009.

Table 1: Species composition and seasonal presence of the Rodrigo de Freitas Lagoon birds community recorded from January 2008 to January 2009.

\begin{tabular}{|l|l|l|l|}
\hline Família/Espécie & Nome Comum & Fo & $\begin{array}{l}\text { Presença } \\
\text { Sazonal }\end{array}$ \\
\hline Phalacrocoracidae & & & \\
\hline Phalacrocorax brasilianus Gmelin, 1789 & biguá & 1,00 & Residente \\
\hline Fregatidae & & & \\
\hline Fregata magnificens Mathews, 1914 & tesourão & 0,84 & Residente \\
\hline Ardeidae & & & \\
\hline Ardea cocoi L,1766 & garça-cinzenta & 0,60 & Visitante \\
\hline Ardea alba (= Egretta alba) L, 1758 & garça-branca-grande & 0,89 & Residente \\
\hline Egretta thula Molina, 1782 & garça-branca-pequena & 0,60 & $\begin{array}{l}\text { Provável } \\
\text { Residente }\end{array}$ \\
\hline Butorides striatus L, 1758 & socozinho & 0,80 & $\begin{array}{l}\text { Provável } \\
\text { Residente }\end{array}$ \\
\hline Nycticorax nicticorax L, 1758 & savacu & 0,23 & Indeterminada \\
\hline
\end{tabular}

Continua... 
continuação.

\begin{tabular}{|c|c|c|c|}
\hline Família/Espécie & Nome Comum & Fo & $\begin{array}{l}\text { Presença } \\
\text { Sazonal }\end{array}$ \\
\hline \multicolumn{4}{|l|}{ Laridae } \\
\hline Larus dominicanus Lichtenstein, 1823 & gaivotão & 0,42 & Visitante \\
\hline \multicolumn{4}{|l|}{ Rallidae } \\
\hline Gallinula galeata Lichtenstein, $1818^{*}$ & frango-d'água-comum & 0,98 & Residente \\
\hline \multicolumn{4}{|l|}{ Alcedinidae } \\
\hline Megaceryle torquata L, 1758 & martim-pescador-grande & 0,42 & Visitante \\
\hline \multicolumn{4}{|l|}{ Cathartidae } \\
\hline Coragyps atratus Bechstein, $1793^{*}$ & urubu-de-cabeça-preta & 0,03 & Acidental \\
\hline \multicolumn{4}{|l|}{ Charadriidae } \\
\hline Vanellus chilensis Molina, 1782 & quero-quero & 0,89 & Residente \\
\hline \multicolumn{4}{|l|}{ Columbidae } \\
\hline Columbia livia Gmelin, 1789 & pomba-comum & 1,00 & Residente \\
\hline Columbina talpacoti Temminck, 1811 & rolinha & 1,00 & Residente \\
\hline \multicolumn{4}{|l|}{ Psitacidae } \\
\hline Brotogeris versicolorus Vieillot, 1818 & periquito-de-cabeça-branca & 0,10 & Indeterminada \\
\hline \multicolumn{4}{|l|}{ Cuculidae } \\
\hline Crotophaga ani L, 1758 & anu-preto & 0,16 & Indeterminada \\
\hline \multicolumn{4}{|l|}{ Trochilidae } \\
\hline Eupetonema macroura Gmelin, 1788 & beija-flor-tesourão & 0,34 & Indeterminada \\
\hline \multicolumn{4}{|l|}{ Apodidae } \\
\hline Streptoprogne zonaris Shaw, 1796 & andorinha-de-coleira & 0,12 & Indeterminada \\
\hline \multicolumn{4}{|l|}{ Furnaridae } \\
\hline Furnarius rufus Gmelin, $1788^{*}$ & joão-de-barro & 0,91 & Residente \\
\hline Certhiaxis cinnamomea * & corruíra-do-brejo & 0,78 & $\begin{array}{l}\text { Provável } \\
\text { Residente }\end{array}$ \\
\hline \multicolumn{4}{|l|}{ Tyrannidae } \\
\hline Elaenia flavogaster Thunberg, 1822 & $\begin{array}{l}\text { guaracava-de-barriga- } \\
\text { amarela }\end{array}$ & 0,10 & Indeterminada \\
\hline Fluvicola nengeta L, 1766 & lavadeira-mascarada & 1,00 & Residente \\
\hline Machetornis rixosus Vieillot, 1819 & suiriri-cavaleiro & 0,49 & Visitante \\
\hline Philohydor lictor Lichtenstein, 1823 * & bentevizinho & 0,15 & Indeterminada \\
\hline Pitangus sulphuratus L, 1758 & bem-te-vi & 1,00 & Residente \\
\hline Tyrannus melancholicus Vieillot, 1819 & suiriri & 0,59 & Visitante \\
\hline \multicolumn{4}{|l|}{ Hirundinidae } \\
\hline Pygochelidon cyanoleuca Vieillot, 1817 & andorinha-pequena-de-casa & 0,98 & Residente \\
\hline \multicolumn{4}{|l|}{ Trogloditidae } \\
\hline Troglodytes aedon Naumann, 1823 & cambaxirra & 0,47 & Visitante \\
\hline Cantorchilus longirostri Vieillot, 1819 * & garrinchão-de-bico-grande & 0,44 & Visitante \\
\hline \multicolumn{4}{|l|}{ Muscicapidae } \\
\hline Turdus rufiventris Vieillot, 1818 & sabiá-laranjeira & 0,61 & $\begin{array}{l}\text { Provável } \\
\text { Residente }\end{array}$ \\
\hline Turdus amaurochalinus Cabanis, 1850 & sabiá-poca & 0,12 & Indeterminada \\
\hline
\end{tabular}

Continua... 
.continuação.

\begin{tabular}{|l|l|l|l|}
\hline Família/Espécie & Nome Comum & Fo & $\begin{array}{l}\text { Presença } \\
\text { Sazonal }\end{array}$ \\
\hline Emberezidae & & & \\
\hline Coereba flaveola L, 1758 & cambacica & 0,29 & Indeterminada \\
\hline Paroaria dominicana L. 1758 ${ }^{*}$ & galo-de-campina & 0,03 & Acidental \\
\hline Thraupis sayaca L, 1766 & sanhaço & 0,29 & Indeterminada \\
\hline Thraupis palmarum Wied, 1823 & sanhaço-do-coqueiro & 0,10 & Indeterminada \\
\hline Sicalis flaveola L, 1758 & canário-da-terra & 0,11 & Indeterminada \\
\hline Icteridae & & & \\
\hline Molothrus bonariensis Gmelin, 1788 & chopim & 0,10 & Indeterminada \\
\hline Passeridae & & & \\
\hline Passer domesticus L, 1758 & pardal & 1,00 & Residente \\
\hline Estrildidae & & & \\
\hline Estrilda astrild L, 1758 & bico-de-lacre & 0,45 & Visitante \\
\hline
\end{tabular}

Fonte: Elaborado pelo autor.

Source: Prepared by the author.

Em termos quantitativos, verificamos que os meses que apresentaram maior riqueza de espécie foram maio (23 espécies), junho (26 espécies), setembro (23 espécies) e outubro (23 espécies). Em razão de um período chuvoso de aproximadamente 10 dias durante o mês de março de 2009, registramos neste mês o menor número de espécie (12).

\section{A Importância da cidadania científica}

Segundo Mamede, Benites e Alho (2017, p.153), a ciência cidadã tem sido marcante para a expansão do conhecimento científico e sua constituição é multidisciplinar, pois permite a participação ativa dos cidadãos em atividades científicas gerando experiência, compreensão e novos conhecimentos tanto para a ciência quanto para o cidadão participante.

No contexto das ciências naturais, Cohn (2008, p. 192) assinala que o termo cientista cidadão refere-se a voluntários que muitas vezes participam como assistentes de campo em estudos científicos, auxiliando no monitoramento da biodiversidade ou outros aspectos socioambientais, e constitui, em sua maioria, de pesquisadores leigos ou amadores que ajudam nas pesquisas por amarem a natureza e a vida ao livre ou porque estão preocupados com as tendências ambientais e as questões pertinentes e desejam contribuir na compreensão, reversão ou mitigação. Apesar de frequentemente não analisarem dados, nem redigirem artigos científicos, os cidadãos cientistas contribuem de maneira eficiente no levantamento de dados cooperando para responder a perguntas científicas e do mundo real (COOPER et al., 2007; COHN, 2008, p. 193).

Mamede, Benites e Alho (2017, p. 155) destacam a importância da ciência cidadã para a conservação da biodiversidade, seja em grandes biomas, seja em reservas ou áreas de proteção ambiental. Os autores assinalam que o trabalho dos cientistas cidadãos vai além da mera coleta de dados, mas se consolida como um aliado da ciência e que só assim ela consegue de cumprir alguns de seus objetivos relacionados com a conservação dos ambientes naturais e da sua 
sociobiodiversidade colaborando na construção de políticas públicas. Segundo os autores, evidencia-se que:

Muitos esforços de cidadão cientista e de cientista cidadão têm contribuído para potencializar o levantamento de informações, de forma voluntária, sobre espécies e seus habitats. Essa interface entre ciência e cidadania, que comunica direitos e responsabilidades de uma sociedade, é interessante ser percebida e investigada. Se por um lado, o cientista possui formação e habilidades para a coleta de informações e exercício de todas as fases do fazer científico, a fim de manter a integridade científica, o mesmo não detém de todas as condições, oportunidades e possibilidades reais para reunir dados de forma abrangente e totalitária. Até porque, essa suposta supremacia não se revela interessante do ponto de vista da valorização da ciência e sua compreensão pública, uma vez que ao ser estimulada a participação social, a ciência ganha aliados e pode, finalmente, cumprir alguns dos seus objetivos, por exemplo, a conservação dos ambientes naturais e sua sociobiodiversidade e a construção de políticas públicas (MAMEDE; BENITES; ALHO, 2017, p.155)

\section{Atualização da Lista}

Os últimos levantamentos da comunidade de aves da Lagoa empreendidos têm demonstrado uma grande variação na quantidade de espécies. O censo mais antigo é o de 1998 realizados por Alves e Pereira (1998, p.114) e o mais recente data de 2004 e foi conduzido por Lagos (2004). Apesar de Alves, Lagos e Vecchi (2012, p. 527) mencionarem um monitoramento que vinha sendo feito entre $1996 \mathrm{e}$ 2005, o qual teria registrado 60 espécies de aves para a Lagoa (incluindo 12 espécies de aves aquáticas), esse trabalho não está disponível na literatura até o momento. Portanto, a listagem mais atualizada que temos é a que está sendo apresentada nesse artigo.

Dentro da nossa proposta de atualizar o levantamento das espécies de aves da Lagoa com a colaboração de observadores, esperamos corrigir erros e distorções em nossa lista e apresentar um panorama mais realista no tocante à situação da comunidade de aves que convivem nessa localidade. A participação nesse projeto de vários pesquisadores, especializados ou não, constitui uma forma mais rápida e eficaz de elucidar determinadas lacunas deixadas pelos métodos de pesquisa tradicionais utilizados à época dos monitoramentos, pois os recursos tecnológicos disponíveis na atualidade permitem a realização de um trabalho mais acurado e eficaz.

Plataformas digitais como o portal Wiki Aves (wikiaves.com.br) também podem ser utilizadas para auxiliar na identificação de algumas espécies e no armazenamento de vocalizações gravadas. As listas elaboradas em campo pelos observadores podem ser cadastradas no site Táxeus (taxeus.com.br), com o objetivo de divulgar as listas de espécies encontradas. 


\section{Descrição de Aspectos Bioecológicos}

De um modo geral, as aves são atraídas por locais onde há condições favoráveis para a busca de alimentos (atividades de forrageamento), postos de pousada, dormida e sítios de nidificação para fins de reprodução. A determinação de espaços destinados às atividades de forrageamento das aves, por exemplo, é de grande importância, pois facilita a localização das espécies em função dos seus hábitos alimentares. Alves, Lagos e Vechi (2012, p.527) realizaram um estudo visando determinar as táticas de forrageamento de oito espécies de aves aquáticas frequentemente encontradas na Lagoa, assim como o uso do espaço por essas aves, incluindo o microhábitat e a distância da margem e constataram a existência de diferenças entre espécies de famílias distintas que coexistem nesse local

No presente estudo verificou-se que Phalacrocorax brasilianus, Egretta alba, E. thula, Ardea cocoi, Megaceryle torquata, Butorides striatus, Nycticorax nycticorax e Larus dominicanus utilizam mais o espelho d'água da Lagoa do que as margens como fonte de alimentos, retirando principalmente peixes. Já espécies como Fluvicola nengeta, Vanellus chilensis, Machetornius rixosus, Pitangus sulphuratus, Columba livia, Columbina talpacoti e Passer domesticus preferem utilizar as margens como fonte de artrópodes, sobretudo insetos. A andorinha Pygochelidon cyanoleuca captura insetos no espaço aéreo próximo à superfície da água. Outras espécies preferem forragear na vegetação localizada nas bordas da Lagoa ou nos arbustos e árvores próximas como Eupetomena macroura, Thraupis palmarum, $T$. sayaca, Tyrannus melancholicus, Turdus rufivenstris, Coereba flaveola e Estrilda astrild.

O biguá $P$. brasilianus é uma das espécies mais comum de aves aquáticas, inclusive na Lagoa Rodrigo de Freitas onde é muito abundante. Porém, a sua biologia no Brasil é praticamente desconhecida (OLMOS; SILVA-E-SILVA, 2003). A espécie é migratória em alguns locais, como em manguezais do Estado de São Paulo (OLMOS; SILVA-E-SILVA, 2001) e residente em outros como na Lagoa Rodrigo de Freitas (RODRIGO; MICHELIN, 2005). Nessa localidade é possível observar biguás usando árvores da vegetação marginal da lagoa como local de pouso e dormida.

Ninhos de frango-d'água G. galeata podem ser avistados frequentemente junto à vegetação de margem da lagoa. Inclusive, esta espécie se beneficiou dos projetos não-governamentais de recuperação da vegetação da lagoa e voltou a frequentar e reproduzir nesta localidade. Casais de frangos-d'águas acompanhados de seus filhotes constituem atualmente uma atração à parte para os frequentadores da Lagoa. $O$ joão-de-barro $F$. Rufus também nidifica no local em árvores da vegetação da borda e o seu ninho característico pode ser facilmente reconhecido.

Consideramos $C$.atratus e $P$. dominicana como espécies acidentais pelo fato de serem avistadas apenas ocasionalmente naquela localidade, não mantendo nenhuma relação direta com a Lagoa. Os urubus podem ser avistados forrageando junto às margens logo após um período chuvoso em decorrência de detritos que se ali acumulam. Já o galo-de-campina é uma das aves mais requeridas pelo tráfico ilegal de aves silvestre e se apresenta disseminada por todo o Estado do Rio de Janeiro em decorrência deste comércio clandestino (SICK, 1997).

O esforço voluntário dos participantes pode resultar em importantes descobertas a respeito da dinâmica da comunidade de aves da Lagoa, inclusive revelando aspectos particulares da biologia de algumas espécies que não foram 
relatados (ou menosprezados) pela ciência convencional. A ciência cidadã tem essa característica de possibilitar ao pesquisador não especializado a oportunidade de contribuir com as suas informações e torná-las disponíveis, diminuindo as distâncias que separam a ciência da sociedade.

Porém, como assinala Bonney et al. (2009), alguns elementos importantes devem ser considerados nessa perspectiva: a padronização da coleta de dados com protocolos claros, a simplificação operacional e o apoio técnico para que os participantes entendam o funcionamento, de modo a manter atrativa e constante essa participação (BONNEY et al., 2009). De grande importância também é a abertura de canais que possibilitem um diálogo permanente e dinâmico entre cientistas especialistas e cientistas amadores com o objetivo de maximizar os resultados das ações conservacionistas, gerando um sentimento de pertencimento, empoderamento, engajamento público e transformação social, beneficiando a todos os atores envolvidos no processo.

\section{Considerações Finais}

Os inúmeros projetos de recuperação da qualidade ambiental da Lagoa Rodrigo de Freitas que já foram empreendidos tanto por ação governamental quanto por iniciativa privada têm contribuído sobremaneira para o aumento da abundância e diversidade de espécies da avifauna local. Avaliações periódicas das condições ambientais e monitoramento das populações de aves são necessários para se acompanhar os resultados desses programas e as melhorias na qualidade de um sistema lacunar.

Considerando o estágio atual de preservação da Lagoa é provável que os participantes consigam realizar um levantamento muito próximo do esperado, com o número de espécies mais ou menos constante ao da lista que foi apresentada. Exceto casos de aves migratórias muito exigentes, a presença sazonal deverá apresentar pequenas variações em relação ao que foi relatado anteriormente desde que não seja introduzida nenhuma variável no processo de observação das aves do local.

Entretanto, mesmo após a regulamentação da Lagoa e do seu espaço circundante como Área de Proteção Permanente, parece que a vocação do local como ponto turístico tem sobressaído em relação ao seu uso como um espaço destinado à preservação da biodiversidade, o que pode ser comprovado pela pouca atenção dada pela mídia nesse aspecto, exceto quando há um evento de mortandade de peixe.

Um experimento de ciência cidadã com destaque para a atividade de birdwatching pode ser um início de um processo de valorização desse espaço lacunar no tocante ao seu enorme potencial ecoturístico. Contudo, temos a plena consciência de que a nossa proposta jamais terá a abrangência de um projeto liderado por alguma entidade conservacionista ou instituição governamental cujo alcance e perspectiva de engajamento provavelmente seriam maiores. 


\section{Referências}

ALEXANDRINO, E. R.; QUEIROZ, O. T. M. M.; MASSARUTTO, R. C. O potencial do município de Piracicaba (SP) para o turismo de observação de aves (Birdwatching). Revista Brasileira de Ecoturismo, v.5, n.1, p.27-52, 2012.

ALVES, M. A. S; E. F.,PEREIRA. Richness, abundance and seasonality of bird species in a lagoon of an urban area (Lagoa Rodrigo de Freitas) of Rio de Janeiro, Brazil. Ararajuba, Brasília, v.6, n.2, pp.110-116, 1998.

ALVES, M. A. S., LAGOS, A. R.; VECCHI, M. B. Uso do hábitat e táticas de forrageamento de aves aquáticas na Lagoa Rodrigo de Freitas. Oecologia Australis v.16, n.3, pp.525-539, 2012.

BERNARDON, B.; NASSAR, P. M. Observação de aves no lago Mamirauá como atrativo para ecoturistas/birdwatchers. UAKARI, v. 8, n. 2, p. 51-66, 2012. Special Issue: Sustainable Tourism.

BIBBY, C. J.; BURGESS, N. D.; HILL D. A. Bird census techniques. London; Academic Press, 257p., 1993.

BONNEY, R.; COOPER, C.B.; DICKINSON, J.; KELLING, S.; PHILLIPS, T.; ROSENBERG, K. V.; SHIRK, J. Citizen Science: a developing tool for expanding science knowledge and scientific literacy. BioScience, v. 59, n.11, pp.977-984, December/2009.

BRANDOLIN, P.; MARTORI, R.; ÁVALOS, M. Variaciones temporales de los ensambles de aves de a reserva natural de fauna laguna de la felipa (Córdoba, Argentina). Hornero, v.22, n.1, pp.1-8, 2007.

BRITO, I. M.; LEMOS, E. E. Evolução geológica e fauna da lagoa Rodrigo de Freitas, Rio de Janeiro. An. Acad. Brasil. Ciênc. V.54, pp.143-164. 1982.

COHN, J. P. Citizen science: can volunteers do real research? BioScience v.58, n.3, pp.192-197, March/2008.

COOPER, C. B.; DICKINSON, J.; PHILLIPS, T.; BONNEY, R. Citizen science as a tool for conservation in residential ecosystems. Ecology and Society v.12, n.2, pp.1$11,2007$.

DIAS, R. A biodiversidade como atrativo turístico: o caso do turismo de observação de aves no município de Ubatuba (SP). Revista Brasileira de Ecoturismo, São Paulo, v.4, n.1, 2011, p.111-122.

DIAS, R.; FIGUEIRA, V. 2010. O turismo de observação de aves: um estudo de caso do município de Ubatuba/SP-Brasil. Revista de Estudos Politécnicos Polytechnical Studies Review. Vol VIII, no 14, 2010, pp.085-096.

FURNESS, R. W.; J. D., GREENWOOD; P. J. DARVIS. Can birds be used to monitor the environment? p. 141. In: R. W. Furness and J. D. Greenwood (Eds). Birds as monitor of environmental changes. London, Chapman \& Hall, 325 p. 1993.

HAYMAN, P.; J., MARCHANT; T., PRATER. Shorebirds: an identification guide. Boston, Hought Mifflin, 412 p., 1986.

MAMEDE, S.; M. BENITES; C. J. R., ALHO. Ciência Cidadã e sua Contribuição na Proteção e Conservação da Biodiversidade na Reserva da Biosfera do Pantanal.

Revista Brasileira de Educação Ambiental (RevBEA) 12(4): 153-164, 2017. 
OLMOS, F.; R., SILVA-E-SILVA. The avifauna of a southeastern Brazilian mangrove swamp. International Journal of Ornithology, Belo Horizonte, v.4, n.3/4, pp.137207, 2001.

OLMOS, F.; R., SILVA-E-SILVA. Guará: ambiente, flora e fauna dos manguezais de Santos-Cubatão, Brasil. São Paulo, Empresa das Artes, 216 p., 2003.

PARRA, H. Z. M., FRESSOLI; M.; LAFUENTE, A. Ciência Cidadã e Laboratórios Cidadãos. Liinc em Revista, Rio de Janeiro, v.13, n.1, p. 1-6, 2017.

RODRIGUES, M.; V. B. MICHELIN. Riqueza e diversidade de aves aquáticas de uma lagoa natural no sudeste do Brasil. Rev. Bras. Zool. V.22, n.4, pp.928-935, 2005.

RUTSCHKE, E. Waterfowl as bioindicators. International Council For Bird Preservation. Technical Publication No. 6, Cambridge, International Council for Bird Preservation, p. 167-172, 1987.

SANTOS, F. C. V.; LIMA, L. B.; NASCIMENTO, M. S.; BRAGA, S. S.; GUZZI, A. O Potencial do Birdwatching na Área de Proteção Ambiental do Delta do Parnaíba (Piauí, Brasil). Revista Brasileira de Ecoturismo, São Paulo, v.12, n.5, pp.854-865. 2019.

SANTORO, A. L.; RICC, R. M. P.; ENRICH-PRAST, A. Lagoa Rodrigo de Freitas: passado e presente. Oecologia Australis v.16, n.3, pp.334-338, Setembro 2012.

SILVA, J. A. D.; NERY, A. S. D. Uma proposta de uso da plataforma Wiki Aves como um facilitador na aprendizagem de temas ambientais relacionados à ornitologia. Thema, v.16, 2019, pp.607-616.

SICK, H. Ornitologia brasileira. Rio de Janeiro, Nova fronteira, 912 p., 1997.

SOUZA, D. All the birds of Brazil: an identification guide. Feira de Santana, Dall, 356 p., 2002.

ZAR, J. H. Biostatistical analysis. London: Prentice-Hall International. 1984.

José Antônio Dias da Silva: Fundação de Apoio à Escola Técnica, Rio de Janeiro, RJ, Brasil.

E-mail: joseantoniodias@live.com

Link para o currículo Lattes: http://lattes.cnpq.br/6132713816505729

Data de submissão: 25 de abril de 2020

Data de recebimento de correções: 16 de maio de 2020

Data do aceite: 16 de maio de 2020

Avaliado anonimamente 